\title{
Announced reward counteracts the effects of chronic social stress on anticipatory behavior and hippocampal synaptic plasticity in rats
}

\author{
Amer Kamal · Johanneke E. Van der Harst • \\ Chantal M. Kapteijn · Annemarie J. M. Baars • \\ Berry M. Spruijt • Geert M. J. Ramakers
}

Received: 3 September 2009 / Accepted: 1 November 2009 / Published online: 17 November 2009

(c) The Author(s) 2009. This article is published with open access at Springerlink.com

\begin{abstract}
Chronic stress causes insensitivity to rewards (anhedonia) in rats, reflected by the absence of anticipatory behavior for a sucrose-reward, which can be reversed by antidepressant treatment or repeated announced transfer to an enriched cage. It was, however, not clear whether the highly rewarding properties of the enriched cage alone caused this reversal or whether the anticipation of this reward as such had an additional effect. Therefore, the present study compared the consequences of the announcement of a reward to the mere effect of a reward alone with respect to their efficacy to counteract the consequences of chronic stress. Two forms of synaptic plasticity, long-term potentiation and long-term depression were investigated in area
\end{abstract}

The first two authors equally contributed to the paper.

A. Kamal · C. M. Kapteijn · G. M. J. Ramakers Department of Neuroscience and Pharmacology, Rudolf Magnus Institute of Neuroscience,

University Medical Centre Utrecht, Universiteitsweg 100,

3584 CG Utrecht, The Netherlands

\author{
A. Kamal ( $\square)$ \\ Physiology Department, \\ College of Medicine and Medical Sciences, \\ Arabian Gulf University, P.O. Box 26671, Manama, \\ Kingdom of Bahrain \\ e-mail: amerha@agu.edu.bh
}

J. E. Van der Harst · C. M. Kapteijn · A. J. M. Baars · B. M. Spruijt

Ethology and Welfare Group, Department of Animals,

Science and Society, Faculty of Veterinary Medicine,

Utrecht University, Yalelaan 2, 3584 CM Utrecht,

The Netherlands

\section{B. M. Spruijt}

Department of Biology, Faculty of BetaSciences,

Utrecht University, Padualaan 8,

3584 CH Utrecht, The Netherlands
CA1 of the hippocampus. This was done in socially stressed rats (induced by defeat and subsequent long-term individual housing), socially stressed rats that received a reward (short-term enriched housing) and socially stressed rats to which this reward was announced by means of a stimulus that was repeatedly paired to the reward. The results were compared to corresponding control rats. We show that announcement of enriched housing appeared to have had an additional effect compared to the enriched housing per se as indicated by a significant higher amount of LTP. In conclusion, announced short-term enriched housing has a high and long-lasting counteracting efficacy on stress-induced alterations of hippocampal synaptic plasticity. This information is important for counteracting the consequences of chronic stress in both human and captive rats.

Keywords Hippocampus - Long-term potentiation · Synaptic plasticity $\cdot$ Stress $\cdot$ Environmental enrichment
Abbreviations
LTP Long-term potentiation
LTD Long-term depression
fEPSP Field excitatory postsynaptic potentials
HFS High-frequency stimulation

\section{Introduction}

Chronic social stress in rats causes insensitivity to rewards indicated by impaired reward-related behavior in defeated and subsequently individually housed rats (Von Frijtag et al. 2000). This impairment is reflected by the absence of an increase in activity in anticipation (i.e. expectation) of a sucrose reward that is announced using a Pavlovian 
conditioning paradigm. Insensitivity to rewards is indicative of an anhedonic state (Von Frijtag et al. 2000), which is considered to be a major symptom of human depression (American Psychiatric Association 1994). This is supported by the fact that administration of an antidepressant (Imipramine) restores the absence of anticipatory behavior for a sucrose reward in socially stressed rats (Von Frijtag et al. 2002). In a previous study we have shown that a regime of regular reward (sucrose) announcements prevented the development of this stress-induced absence of anticipatory behavior (Van der Harst et al. 2005). Furthermore, this study revealed that repeated announced transfer to an enriched cage restored the anticipatory response in socially stressed rats. This might be due to the highly rewarding property of the enriched cage as revealed by other research that showed that rats display a similar level of anticipation for an enriched cage as for sexual contact (Van der Harst et al. 2003a). We hypothesized that announcement of a reward has an additional effect compared to the mere receipt of a reward on the alteration of chronic-stressinduced reward insensitivity.

Stress is known to dramatically affect the synaptic plasticity of the hippocampus (Kim and Yoon 1998; De Kloet et al. 1999; McEwen 1999), which is a brain region that is particularly sensitive to previous (stressful) experiences (Foy et al. 1987; Foster et al. 1996; Carboni et al. 2006). In chronically stressed rats artificially induced sustained enhancement of synaptic strength (long-term potentiation: LTP) by high frequency stimulation (HFS) of the hippocampus is impaired (Diamond and Rose 1994; Kim et al. 1996; Pavlides et al. 2002; Buwalda et al. 2005) and can be restored by treatment with an antidepressant (Von Frijtag et al. 2001; Shakesby et al. 2002).

Therefore, in the present study the forwarded hypothesis that activation of reward systems by the announcement of reward counteracts the effect of chronic stress is investigated at the level of synaptic plasticity of the hippocampus. This is done by comparing the consequences of announcement of a reward to the mere receipt of a reward with respect to their efficacy to counteract the effects of chronic social stress in rats. To that end, defeated rats were, after long-term individual housing as a part of the social stress paradigm (Von Frijtag et al. 2000), transferred to an enriched cage for several times during a short period (30 min/10 days). For another group an announcement of the transfer to this cage was included in the treatment. To validate the results of the behavioral treatment, a socially stressed group received a pharmacological treatment by means of chronic administration of an antidepressant, imipramine. Our results show that announcement of enriched housing had an additional effect compared to the enriched housing alone as indicated by a significant higher amount of LTP. This finding might be of relevance for neurtralizing the effects of chronic stress in both human and captive rats.

\section{Experimental procedures}

The experiments have been performed in adherence to the legal requirements of The Netherlands concerning research on laboratory animals, and have been approved by the Ethical Committee of Utrecht University.

Subjects, housing, and general procedures

Forty-two male Wistar rats (23 socially-stressed, and 19 control) (HsdCpb:WU, Harlan, The Netherlands) weighing approximately $200 \mathrm{~g}$ at their arrival were initially socially housed ( $n=3$ per cage) in Makrolon type IV cages (Tecniplast, Milan, Italy). The animals were kept under a reversed light/dark cycle (bright white light 20000800 hours; dim light ( $25 \mathrm{~W})$ : $0800-2000$ hours) in a temperature-controlled room $\left(21 \pm 2^{\circ} \mathrm{C}\right)$ with background music. Water and food (Hope Farms ${ }^{\mathrm{TM}}$ standard rat chow) were available ad libitum. Cleaning of the cages and weighing of the rats was conducted once per week. After 2 weeks of habituation and acclimatization, the experimental procedures were started. At this time the rats had a mean bodyweight of $320 \pm 2.26 \mathrm{~g}$.

\section{Experimental design and procedures (Table 1)}

All experimental procedures were conducted during the dark phase. The rats were subjected to a social stress paradigm that consisted of repeated defeat during forced introduction in the territory of a dominant male rat. As a part of the social stress (St) paradigm (see Von Frijtag et al. 2000) the experimental rats were individually housed (in Makrolon type III cages) immediately after the first defeat session.

After 82 days the rats were subjected to one of two behavioral treatments (enriched housing without announcement $[\mathrm{St}-\mathrm{E}]$ or enriched housing preceded by an announcement [St-AE]) or received no treatment (St-W). Enriched housing was made by increasing the cage surface area, adding different objects, compartmentalization, mesh-wire shelters, tunnel passages, and addition of gnawing-wood pieces. The behavioral treatment consisted of short periods (30 min) of enriched housing (E) once per day during 10 days or included an announcement of the transfer to the enriched housing condition (AE).

After a total of 121 days after the first defeat-session (thus, 28 days after termination of the behavioral treatment, see Table 1), an anticipation-on-sucrose test was conducted to assess whether the behavioral treatments (E- and AE-) had been effective to reverse the earlier reported 
impairment in reward-related behavior. Nine days after this test, sucrose preference was assessed by measuring the total amount consumed during $24 \mathrm{~h}$ (see section "Sucrose preference").

To validate the effects of the behavioral treatment, part of the socially-stressed group which received no behavioral treatment was treated by administration of an antidepressant (Imipramine) (St-Im). Another part received the control treatment of oral injections with the vehicle solution (water) (St-W). This pharmacological treatment extended during the last 8 weeks of the experiment (see Table 1). The same procedures were followed for another four groups of control rats $(\mathrm{Co})$. These groups were not subjected to social-stress paradigms. Two groups of these rats were receiving one of two behavioral treatments (enriched housing without announcement [Co-E], or enriched-housing with announcement [Co-AE]). The third, control, not socially-stressed group, received no pharmacologic treatment (Co-W), while the fourth control group was treated by administration of the antidepressant imipramine (Co-Im).

After a total of 198-222 days after the first defeatsession, synaptic plasticity in the hippocampus was determined to assess the effects of the different treatments at the level of brain functioning and to validate the results of the behavioral tests. For this, the rats were killed and the brains were removed (see section "Electrophysiology"). The final experimental design for these electrophysiological measurements consisted of eight experimental groups: (1) St-E, (2) Co-E, (3) St-AE, (4) Co-AE, (5) St-Im, (6) Co-Im, (7) $\mathrm{St}-\mathrm{W}$, and (8) Co.W. The time schedule of the procedures, treatments, and performed tests/experiments is presented in Table 1.
Social defeat procedure

The social defeat procedure consisted of daily residentintruder sessions on five consecutive days. Each defeat session lasted for 20 min: a 5-min pre-, a 10-min fight-, and a 5-min post-phase. During the pre- and post-phases the experimental rat (intruder) was positioned behind a transparent, perforated barrier in the home-cage $(63 \times$ $25 \times 33 \mathrm{~cm}$ ) of a dominant male Long-Evans rat (LE/CpbHsd, Harlan, UK). These residents were housed with a sterilized female rat to stimulate territorial aggression; this female was removed from the home-cage before each defeatsession. The Long-Evans strain was selected for their strong physical condition, readiness to attack, and fightingtactics (inhibition of aggression when intruder displays submissive behavior, thus minimizing the risk of injuries). The fight-phase was initiated and terminated by, respectively, removing or replacing the barrier. During the fight-phase the experimental rat was attacked and lost the fight in all cases.

\section{Treatments}

As mentioned earlier, the behavioral treatment consisted of short periods (30 min) of enriched housing (E) once per day during 10 days or included an announcement of the transfer to the enriched housing condition (AE). For this, the homecages of the rats were placed next to enriched cages. The rats were always transferred to the same enriched cage to prevent a novelty effect. During the transfer, the lids were lift of the cages; after several sessions, the rats usually jumped over to the enriched cage by themselves. If not, they were gently guided to the enriched cage.

Table 1 Time schedule of the treatments and performed measurements presented as number of days after the first day of individual housing $(=$ after the first defeat session)

\begin{tabular}{|c|c|c|}
\hline Days & & Group \\
\hline $0-5$ & Defeat + individual housing after first session & \\
\hline $6-82$ & Individual housing & \\
\hline \multirow[t]{3}{*}{$83-93$} & Behavioral treatment: & \\
\hline & Enriched cage, 30 min per day during 10 days & $($ St-E, Co-E) \\
\hline & Announced transfer to enriched cage ( $30 \mathrm{~min} \mathrm{pd}, 10$ days) & $(\mathrm{St}-\mathrm{AE}, \mathrm{Co}-\mathrm{AE})$ \\
\hline \multirow[t]{2}{*}{$121-131$} & Behavioral test: Anticipation of sucrose & \\
\hline & Assessment of the effect of the behavioral treatment on reward-sensitivity & \\
\hline $140-143$ & Sucrose consumption test (two-bottle test $(24 \mathrm{~h}$ ): water vs. $1 \%$ sucr/water vs. $5 \%$ sucr) & \\
\hline \multirow[t]{2}{*}{$159-222$} & Pharmacological treatment: St, Co + Imipramine & (St-Im, Co-Im) \\
\hline & Control: St, Co + vehicle (demi-water) & $(\mathrm{St}-\mathrm{W}, \mathrm{Co}-\mathrm{W})$ \\
\hline \multirow[t]{2}{*}{$198-222$} & Electrophysiology hippocampal slices & \\
\hline & (LTD) in the CA1 area of the hippocampus, in vitro & \\
\hline
\end{tabular}

The control groups (Co) of animals were not subjected into social-stress paradigm 
The AE groups were trained to associate a combined visual-auditory stimulus (light flash + sound of a bell) with the transfer to the enriched cage by means of repeated pairings. The interval between the announcement and the actual transfer was gradually prolonged to $10 \mathrm{~min}$, thus increasing the activation of the reward system.

The pharmacological treatment consisted of daily (oral) injections with the antidepressant imipramine $(20 \mathrm{mg} / \mathrm{kg}$ per $0.5 \mathrm{ml}$ water; Sigma-Aldrich, Germany). Because of its bitterness, the solution was administered directly into the stomach. This was accomplished by means of long bended probe with a rounded top that was gently slid in the esophagus of the rats. After several sessions, most of the rats would swallow the probe automatically. The rats were treated with imipramine for at least 3 weeks before killing for electrophysiological measurements.

\section{Anticipation-of-sucrose}

Anticipatory behavior was induced by a Pavlovian conditioning set-up in which an initially neutral stimulus (conditioned stimulus; CS) was repeatedly paired with a sucrose-reward (unconditioned stimulus; US). The delay between the offset of the CS and the onset of the US was progressively increased to $10 \mathrm{~min}$ over 35 trials (see Von Frijtag et al. 2002). The CS consisted of a repetition of a sound (produced by a keyboard) and light flashes (three times) which was different in duration and tone from the stimulus used before for the AE- group. To investigate the behavioral response to the CS, the animals were observed before training to determine baseline activity and after 35 training trials. For this, behavior displayed in the CS-US interval was recorded on videotape during trial 0 (baseline activity) and trial 35 . For the observational sessions, the animals were transported to a separate room and placed individually in an observation cage $(63 \times 25 \times 33 \mathrm{~cm}$, $1 \times \mathrm{w} \times \mathrm{h}$ ) (during the habituation period the animals have been subjected to these procedures to prevent novelty effects). Behavior was observed and analyzed from videotape using the computer program 'The Observer' (Noldus Information Technology, Wageningen, The Netherlands). The experimenter that analyzed the behavioral data was blind with respect to the group membership of the animals. Activity displayed in the CS-US interval (reflected by the frequency or transitions of behavioral elements) was used as parameter for anticipation.

\section{Sucrose preference}

First, the normal water consumption during $24 \mathrm{~h}$ was measured. Subsequently, preference for sucrose was measured by means of a two-bottle consumption test with water versus $1 \%$ sucrose solution or versus $5 \%$ sucrose solution.
For this, half of the animals received a water bottle and a sucrose bottle with $1 \%$ sucrose solution, whereas the other half received water and a $5 \%$ sucrose solution. The total amount consumed out of each bottle was assessed after $24 \mathrm{~h}$ by reweighing the preweighed bottles. After 2 days, the consumption test was repeated: the animals that had received $1 \%$ sucrose solution during the first session now received a $5 \%$ sucrose solution and a water bottle and vice versa.

\section{Electrophysiology}

Rats ( $n=6$ per experimental group) were killed for electrophysiological measurements in the CA1 region of the hippocampus (see Table 1). The rats were decapitated after a short period of inhalation of anesthesia with isoflurane. Subsequently, the brains were rapidly removed, placed in ice-cold medium and slices $(450 \mu \mathrm{m})$ were prepared as described (van Dam et al. 2004). Hippocampal slices were incubated in artificial cerebrospinal fluid (ACSF) of the following composition in $\mathrm{mM}$ : $\mathrm{NaCl} 124, \mathrm{KCl} 3.3, \mathrm{KH}_{2} \mathrm{PO}_{4}$ 1.2, $\mathrm{MgSO}_{4} 1.3, \mathrm{CaCl}_{2} 2.5, \mathrm{NaHCO}_{3} 20$ and Glucose 10.0, constantly gassed with $95 \% \mathrm{O}_{2} / 5 \% \mathrm{CO}_{2}$. Thereafter, slices were transferred to the recording chamber and perfused with ACSF at a rate of $2 \mathrm{ml} / \mathrm{min}$ at $30^{\circ} \mathrm{C}$. Field excitatory postsynaptic potentials (fEPSPs) were recorded in stratum radiatum of area CA1 of the hippocampus using glass micro-electrodes with a tip diameter of $3-5 \mu \mathrm{m}$ and a $0.5-\mathrm{M} \Omega$ resistance filled with ACSF. Bipolar stainless steel electrodes of $100 \mu \mathrm{m}$ placed on Schaffer collateral fibers were used as stimulation electrodes. The stimulus intensity that evoked half-maximum amplitude of fEPSP was used as stimulation intensity throughout the experiment. Only slices that displayed maximal fEPSP responses of more than $1 \mathrm{mV}$ were included in the study. As soon as a stable baseline was found, recording of this baseline response was conducted for $15 \mathrm{~min}$ with test stimuli given at a rate of $0.05 \mathrm{~Hz}$ (double pulses; interstimulus interval of $50 \mathrm{~ms}$ ). The average slope of the baseline responses were set to $100 \%$ and the slopes during the experiments are expressed as percentages of the baseline slope. The slope of the fEPSP was calculated in the linear part of the downward deflection of the trace. Recorded signals were digitized at $5 \mathrm{kHz}$ using a Micro 1401 interface (CED Ltd, Cambridge, England) and then stored and analyzed using Signal-2 software (CED Ltd, Cambridge, England). HFS composed of 100 pulses per second $(100 \mathrm{~Hz})$ were used to induce longterm potentiation (LTP), and low-frequency stimulation (LFS) composed of 900 pulses given in frequency of $1 \mathrm{~Hz}$ (for $15 \mathrm{~min}$ ) were used to induce long term depression (LTD). The Paired-Pulse Facilitation ratio (PPF) was defined as the slope of the second fEPSP response divided by the slope of the first fEPSP. From each animal several 
hippocampal slices were made. Each LTP or LTD experiment was done on a separate naïve slice. This was to avoid any interaction as a consequence of previous stimulation. Attention was paid to place the stimulating and recording electrodes in the same part of the hippocampus in all the experiments. We started with LTP experiments by using HFSs, and this was followed by LTD experiments by using LFSs. This sequence was followed for all the animals tested. Every experiment designed to test the effect of specific frequency of stimulation on the synaptic plasticity of the hippocampus was performed on a separate naïve slice.

\section{Statistical analysis}

Data were expressed as group means with standard error of the mean (SEM). The Statistical Package for Social Sciences (SPSS) was used for statistical analysis.

\section{Bodyweight}

Difference between groups in bodyweight at every separate week during the experiment was analyzed by means of independent samples $t$ tests. A two-way ANOVA for repeated measures was conducted to analyze differences in weight gain over the course of the experiment (withinsubjects factor: time; between-subjects factors: defeat and therapy).

\section{Anticipation-of-sucrose}

The total frequency of all displayed behavioral elements, reflecting behavioral transitions and thus activity, was calculated as a measure for reward sensitivity. The behavioral elements that were observed were exploration, rearing, sitting, lying, sniffing, hopping, scanning, freezing, grooming, circuling, digging, gnawing, and drinking. The data were expressed as mean frequency per minute. Significant increases in activity in response to the CS after repeated pairings of the CS with the sucrose solution were analyzed by comparing the activity before training (baseline) with the activity after 35 training trials. This was done by means of paired samples $t$ tests.

\section{Sucrose preference}

The intake of water and sucrose-solutions was determined by reweighing the pre weighed bottles after $24 \mathrm{~h}$. Sucrose preference was determined by within- group comparison of the consumed amount of water and the two concentrations of sucrose solutions by means of paired samples $t$ tests. Possible differences between groups were analyzed by means of independent samples $t$ tests.

\section{Electrophysiology}

Between-group differences in fEPSP-slopes at approximately $1 \mathrm{~h}$ after HFS were analyzed by means of the nonparametrical Mann-Whitney $U$ test. For this, mean values $( \pm \mathrm{SEM})$ of the recordings of 55-60 min (10 measurements) after HFS were calculated. Within-group changes in synaptic activity were analyzed by comparing the absolute baseline responses with that $1 \mathrm{~h}$ after the application of HFS or LFS. This was done by means of Wilcoxon-signed rank tests.

\section{Results}

The weight curve of the mean bodyweight per week shows that the bodyweight gain increases to a lesser extent during and shortly after the defeat- period in all groups (Fig. 1). Analysis of the effects of the different treatments and experimental procedures reveals that no group differences are present during the defeat $(p>0.05)$, or during the behavioral treatment in the first week $(p>0.05$, and the second week $(p>0.05)$. An ANOVA for repeated measures that was used to analyze the effect of the behavioral treatment over time (from the week before until the week after the treatment) reveals that no treatment- effect on bodyweight was present $(p>0.05)$. Concerning the pharmacological treatment, an effect of imipramine-treatment on the bodyweight over time (week before treatment until decapitation) was detected: Imipramine caused a significant decrease in bodyweight over time $(p<0.05)$.

Analysis of the difference in activity in response to the CS between pre- and post- training revealed that both treatment-groups (St-E and St-AE) showed a significant increase in activity (Related samples $t$ test (pre- vs. posttraining): St-E, $p<0.05$; St-AE, $p<0.05$ ) reflecting anticipation, and thus, reward- sensitivity (Fig. 2). The control group (St-W) did not show an anticipatory increase in activity as compared to baseline activity $(p>0.05)$, indicating that, without treatment, chronic social stress results in insensitivity to rewards (anhedonia) - a symptom that we have shown before in several other studies (Von Frijtag et al. 2000, 2001, 2002; Van der Harst et al. 2005). Baseline activity (trial 0) was not different between the three groups ( $p>0.1$ for all cases). General activity differences between groups at trial 35 were only present between St-AE and St-W $(p<0.05)$. The mean consumption during the 5-min access to the $5 \%$-sucrose solution during the trials was not affected by the different treatments (Table 2; $p>0.05$ for all comparisons). 
Fig. 1 Bodyweight of socially stressed rats over the time course of the experiment (for details of the time schedule on $x$ axis see Table 1), presented as mean value $\pm \mathrm{SEM}$. The rats were subjected to a behavioral treatment (enrichment (St-E, $n=6$, open square) or announced enrichment (St-AE, $n=5$, filled square)), a pharmacological treatment (imipramine (St-Im, $n=6$, open triangle)) or to the control (vehicle: water) treatment (St-W, $n=6$, filled triangle). On the $x$ axis, the procedures and treatments are indicated

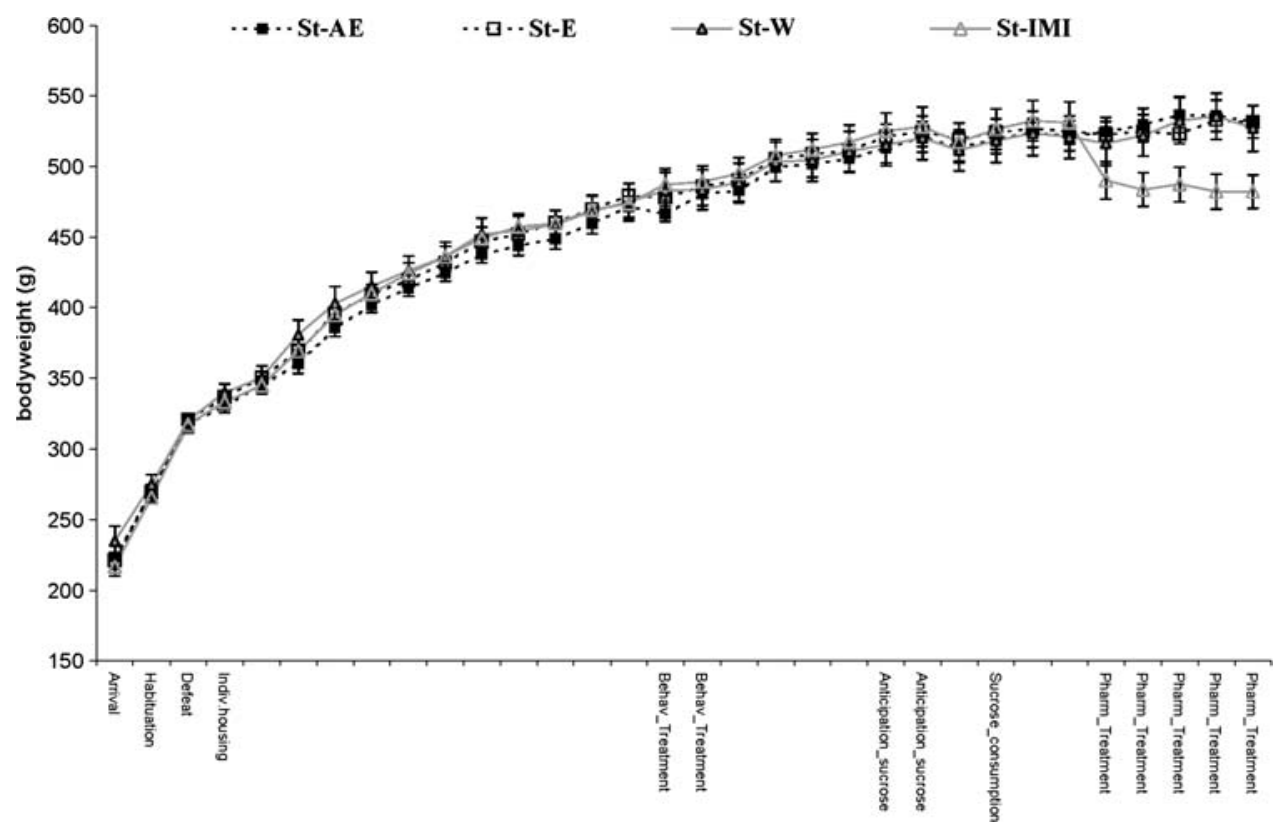

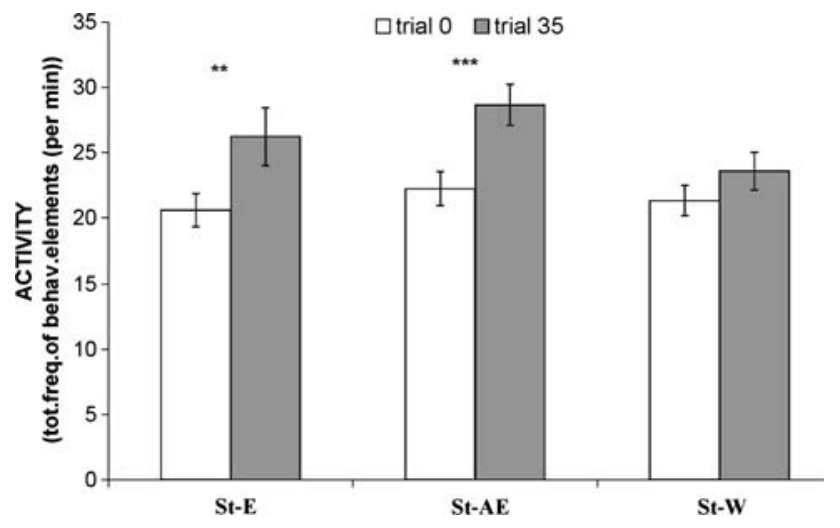

Fig. 2 Anticipation of sucrose $(5 \%, 5 \mathrm{~min})$ : Assessment of the presence of an appetitive response in socially stressed rats that were subjected to a behavioral treatment (enrichment (St-E); announced enrichment (St-AE)) or to the control treatment (St-W). Presented as the activity in the CS-US interval (represented by the total frequency of all behavioral elements) ( \pm SEM) during trial 0 (pre-training; basal level of activity) and trial 35 (post- training). Significant differences in activity between pre- and post-training are indicated with an asterisk $(* * p<0.01 ; * * * p<0.001)$

The 24-h consumption test indicated that both the treatment- and non-treatment groups showed a clear preference for the sucrose bottle over the water bottle. This was true for both the 1\%- (Paired samples $t$ test; water vs. 1\%: St-W, $p<0.05$; St-E, $p<0.05$; St-AE, $p<0.05)$ and the 5\%- solution (water vs. 5\%: St-W, $p<0.05$; St-E, $p<0.05$; St-AE, $p<0.05)$. Furthermore, it appeared that in all groups the amount of consumed sucrose was equal in the $1 \%$ consumption test and the 5\% consumption test (Paired samples $t$ test; $1 \%$ vs. 5\%: $p>0.05$ for all groups). Also, the total consumed amount of both 1 and $5 \%$ sucrose exceeded the normal water consumption during $24 \mathrm{~h}$ that was determined
Table 2 Sucrose consumption of socially stressed rats that had received behavioral treatment (enrichment (St-E); announced enrichment (St-AE) or the control treatment (St-W)

\begin{tabular}{llll}
\hline $24 \mathrm{~h}$ & $\begin{array}{l}\text { Treatment: } \\
\text { enriched } \\
\text { housing (St-E) }\end{array}$ & $\begin{array}{l}\text { Treatment: } \\
\text { announced } \\
\text { enriched } \\
\text { housing (St-AE) }\end{array}$ & $\begin{array}{l}\text { No treatment } \\
\text { (St-W) }\end{array}$ \\
\hline $\begin{array}{c}\text { Single bottle } \\
\text { water }\end{array}$ & $17.10 \pm 1.52$ & $18.2 \pm 2.87$ & $19.0 \pm 4.0$ \\
$\begin{array}{c}\text { Two bottles } \\
\text { water 1\% } \\
\text { sucrose }\end{array}$ & $0.7 \pm 0.26$ & $1.0 \pm 0.21$ & $0.89 \pm 0.26$ \\
$\begin{array}{c}\text { Two bottles } \\
\text { water 5\% } \\
\text { sucrose }\end{array}$ & $1.3 \pm 0.26$ & $0.6 \pm 0.27$ & $0.78 \pm 0.22$ \\
\end{tabular}

Consumption was measured during a 24-h test with two bottles (water and sucrose ( 1 or $5 \%)$; data are presented as mean values ( \pm SEM)

by a single-bottle test (Paired samples $t$ test; $p<0.05$ for all groups). No differences between either of the groups existed for the consumed amount of 1\% sucrose, 5\% sucrose or water (One-way ANOVA, between-group differences: $p>0.05$ in all cases).

Basal excitatory synaptic transmission and two forms of activity-dependent synaptic plasticity were determined in hippocampal slices from eight different groups.

The rats were classified into the following main groups: rats subjected to social stress $(\mathrm{St})$ and control rats $(\mathrm{Co})$. In each main group there were four subgroups: enriched housing without announcement (St-E and Co-E), or enriched housing preceded by an announcement (St-AE and Co-AE). Another group of rats was treated with an antidepressant (imipramine) (St-Im and Co-Im) or vehicle solution (water) 
Table 3 Mean values ( \pm SEM) of stimulation intensities to evoke half-maximal fEPSP, fEPSP amplitude and PPF ratio of the four groups (enrichment (EH, $n=6)$, announced enrichment (AEH, $n=5)$ ), a pharmacological treatment (imipramine (CON-IMI, $n=5)$ ), vehicle treatment (CON-W, $n=6)$ )

\begin{tabular}{lccc}
\hline & $\begin{array}{l}\text { Stimulus } \\
\text { intensity }(\mu \mathrm{A})\end{array}$ & Amplitude & $\begin{array}{l}\text { fEPSP }(\mathrm{mV}) \\
\text { PPF ratio }\end{array}$ \\
\hline A-EH & $89 \pm 9$ & $0.58 \pm 0.12$ & $1.58 \pm 0.21$ \\
EH & $94 \pm 11$ & $0.61 \pm 0.15$ & $1.41 \pm 0.19$ \\
CON-IMI & $101 \pm 16$ & $0.57 \pm 0.12$ & $1.47 \pm 0.15$ \\
CON-W & $87 \pm 7$ & $0.53 \pm 0.13$ & $1.43 \pm 0.16$ \\
\hline
\end{tabular}

(St-W and Co-W). There were no differences in the stimulation intensities to evoke the half maximal fEPSP or in the amplitude and slope of the fEPSPs between all the experimental groups (Table 3, and see insets of Fig. 3a for typical examples). In addition, the amount of paired-pulse facilitation (indicative of presynaptic alterations) was not different between the four groups (see also Table 3 and insets to Fig. 3a).

High frequency stimulation (HFS) of afferent fibers did not result in LTP induction in the social stress group without treatment (St-W, $77.3 \pm 6.6 \%$ of the baseline values, $n=6$ ). This group showed rather depression of the synaptic transmission. The within-group analysis for the effect of HFS on synaptic transmission in the other three groups revealed a significant increase in the slope of the fEPSP $60 \mathrm{~min}$ after HFS in comparison to the baseline fEPSP slope (Wilcoxon $p<0.05$, St-E, $n=6$; St- AE, $n=5$; St-Im, $n=6$ ). The expression of LTP in the slices of the rats that received the enrichment-treatment was significantly higher (St-E: $116.8 \pm 2.7 \%$ ) than that of the non-treated group (Mann-Whitney $U: p<0.05$ ). This was also true for the rats that received announced transfers to the enriched cage (St-AE: $203.3 \pm 23.03 \%, p<0.05$ ) (Fig. 3). Furthermore, the slope of the fEPSP of St-AE was significantly higher than that of St-E $(p<0.05)$ which indicates that the announcement (thus inducing anticipation) had an additional effect. Concerning the pharmacological treatment, the fEPSP after HFS of the imipramine-treated group (St-Im, $138.1 \pm 10.3 \%$ ) was significantly higher than that of the water-treated group. Treatment of socially stressed rats with imipramine was more effective in reversing LTP defects than treatment of the rats by enriched housing (Table 4).

Data from non-stressed control rats showed that rats without any treatment (pharmacological or behavioral) had LTP of $145.1 \pm 19.2 \%$ of the baseline values $(n=4$, $p<0.05$ ) (Table 4). Control rats treated with imipramine showed significant LTP induction of $199 \pm 28.7 \%$ of the baseline values $(n=4, p<0.05)$. HFS evoked significant potentiation in both Co-E and Co-AE groups of rats as well
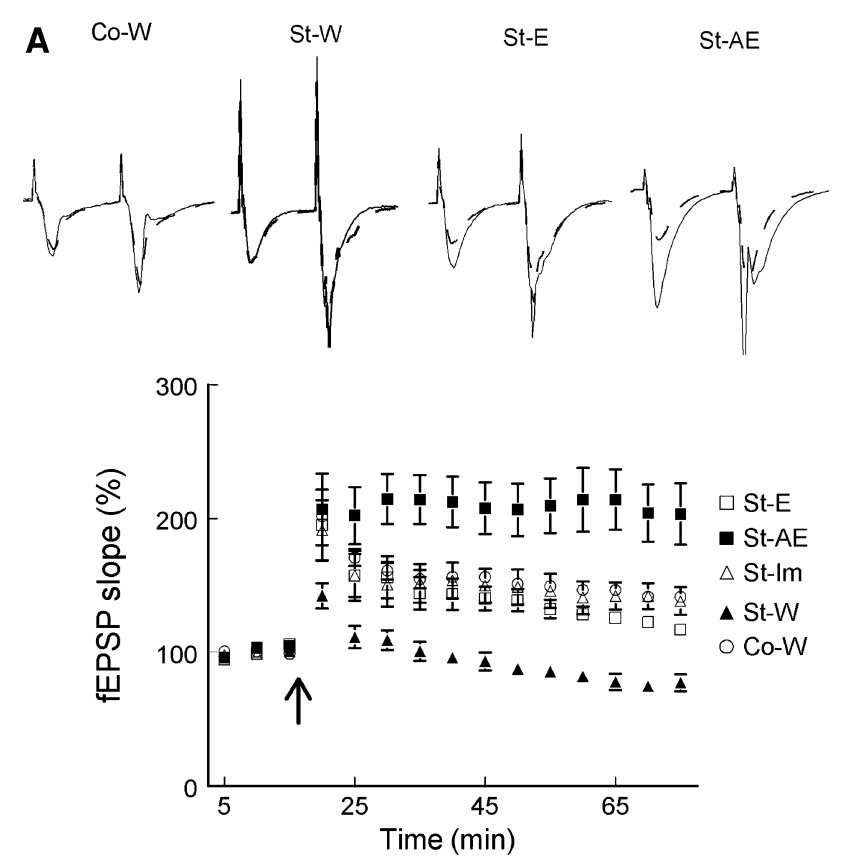

B

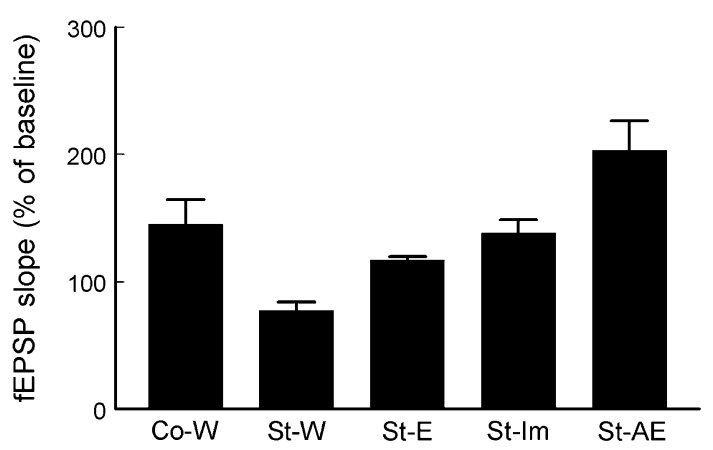

Fig. 3 The effect of high-frequency stimulation (HFS; $100 \mathrm{~Hz}, 1 \mathrm{~s}$ ) in the CA1 area of hippocampal slices from socially stressed rats that were subjected to a behavioral treatment (enrichment (St-E, $n=6)$ or announced enrichment (St-AE, $n=5)$ ), a pharmacological treatment (imipramine (St-Im, $n=5)$ ) or to the control (vehicle: water) treatment $(\mathrm{St}-\mathrm{W}, n=6)$ ). One control (not socially stressed) group, $\mathrm{Co}-\mathrm{W}$, is also presented. The data from the other control (not socially-stressed) groups are summarized in Table 3. a Averaged time course, presented in the 5-min bins, showing that socially stressed rats with control treatment (St-W) show no LTP but a decrease in the slope of the fEPSPs. The AE treatment induced the largest amount of LTP and the imiparamine and E treatment resulted in intermediate amounts of LTP. Data are presented as mean values $( \pm$ SEM) of the relative slope of fEPSPs measured before and after HFS. Inset typical examples of the average (15 sweeps) of fEPSPs evoked in slices from the Co-W group and differentially treated socially stressed rats (St-W, St-E, and St-AE groups) before (interrupted line) and $60 \mathrm{~min}$ after (solid line) HFS. b The average change in the slope of the fEPSP in the last $15 \mathrm{~min}$ of the experiment $(t=60-75 \mathrm{~min})$

$(227.2 \pm 30.7 \%, n=5, p<0.05$, and $192.9 \pm 16.9 \%, n=6$, $p<0.05$ of baseline values respectively). However, comparison between the two groups Co-E and Co-AE showed no significant difference in LTP expression $(p>0.05)$. Comparison of the other groups, on the other hand, showed 
Table 4 Summary of all the electrophysiology results in all the groups

\begin{tabular}{lll}
\hline Group & Average LTP \pm SEM $(n)$ & Average LTD \pm SEM $(n)$ \\
\hline St-E & $116.8 \pm 2.7(n=6)$ & $75.5 \pm 15.9(n=4)$ \\
Co-E & $227.2 \pm 30.7(n=5)$ & $65.2 \pm 4.1(n=4)$ \\
St-AE & $203.3 \pm 23(n=5)$ & $69.9 \pm 7.5(n=5)$ \\
Co-AE & $192.9 \pm 16.9(n=6)$ & $75.6 \pm 12.3(n=5)$ \\
St-Im & $138.1 \pm 10.3(n=5)$ & $93.2 \pm 16.4(n=6)$ \\
Co-Im & $199 \pm 28.7(n=4)$ & $68.9 \pm 8.5(n=4)$ \\
St-W & $77.3 \pm 6.6(n=6)$ & $79.9 \pm 10.8(n=5)$ \\
Co-W & $141.4 \pm 2.6(n=6)$ & $63.3 \pm 12.8(n=4)$ \\
\hline
\end{tabular}

The values represent the averaged last 5 min slope of the fEPSPs $1 \mathrm{~h}$ after HFS (in case of LTP) or LFS (in case of LTD)

that announced enriched-housing after social stress reversed the LTP induction defect into normal LTP, comparable to the LTP recorded in control rats (Table 4). Enriched housing alone (St-E) did not reverse the LTP defect in socially stressed rats.

Following LFS (1 Hz train of stimuli for $15 \mathrm{~min}$ ), there was a non-significant depression in the slope of the fEPSP measured $60 \mathrm{~min}$ after the stimulation train in the St-E (75.8 $\pm 15.9 \%$ of the baseline values, $n=4, p>0.05)$ and the St-Im $(93.2 \pm 16.4 \%$ of the baseline values, $n=6$, $p>0.05$ ) group of rats (Fig. 4; Table 4). Control rats (Co-W rats to these groups, however, showed significant depression of the synapses $60 \mathrm{~min}$ after the conditioning LFS $\quad(65.2 \pm 4.1 \%, \quad n=4, \quad p<0.05$ in Co-E, and $68.9 \pm 8.5 \%, n=4, p<0.05$ in Co-Im groups) (Table 4). LFS on the other hand resulted into significant induction of LTD in the St-AE group $(69.9 \pm 7.5 \%$ of the baseline values, $n=5, p<0.05)$ and the St-W $(79.9 \pm 10.8 \%$ of the baseline values, $n=5, p<0.05)$. However, between-group differences measured by Mann-Whitney $U$ test showed that the depression in the fEPSP was not significantly different $(p>0.05)$ in all the groups.

In Fig. 5, the frequency- response relationship in the CA1 field of the hippocampus of both groups is depicted. We investigated the effect of environment enrichment with announcement (St-AE) versus environment enrichment alone (St-E) on the dynamic range of synaptic transmission. The synaptic plasticity range, the amplitude of the fEPSP slope between the state of depression (LTD), and potentiation (LTP), was higher (about $133.4 \%$ of the baseline values) in the St-AE group than in the St-A group (about $41.3 \%$ of the baseline values) (Fig. 5). The plasticity range of the hippocampus synapses in the comparable control (not socially-stressed) group (Co-AE) was $117.3 \%$ of the baseline value. No significant difference $(p>0.05)$ was calculated between the Co-AE and St-AE groups.
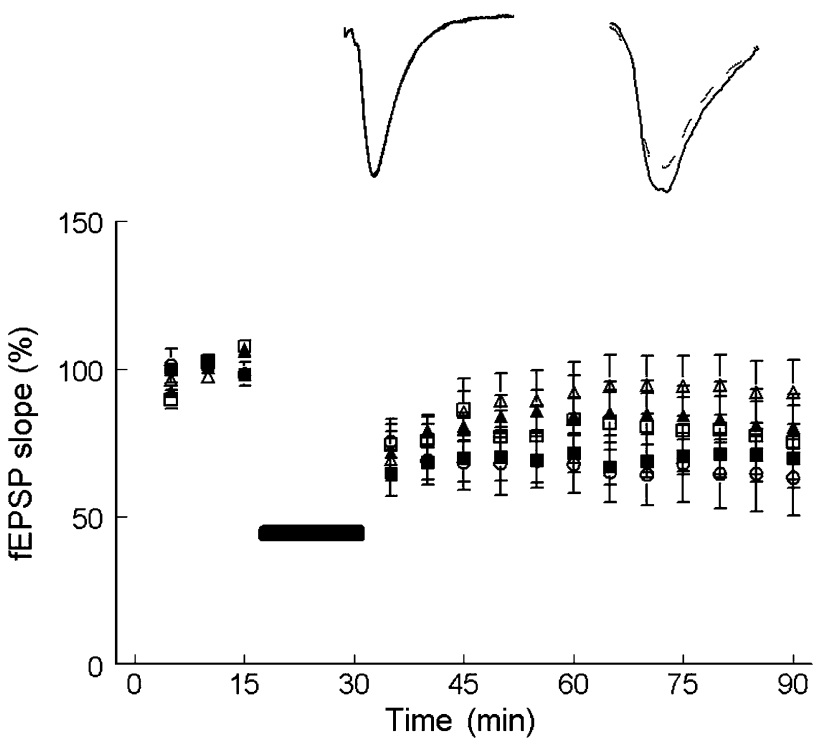

Fig. 4 The effect of low-frequency stimulation (LFS; $1 \mathrm{~Hz}, 15 \mathrm{~min}$ ) in the CA1 area of hippocampal slices from socially stressed rats that were subjected to a behavioral treatment (enrichment (St-E, $n=4)$ or announced enrichment (St-AE, $n=5)$ ), a pharmacological treatment (imipramine (St-Im, $n=6)$ ) or to the control (vehicle: water) treatment (St-W, $n=6$ ). One control (not socially- stressed rats) group is presented $(\mathrm{Co}-\mathrm{W})$. The data from the other three control (not sociallystressed) groups of rats are summarized in Table 3. After $60 \mathrm{~min}$ of the LFS train, slices from St-AE, and St-W showed significant long-term depression (LTD). The other two groups expressed non-significant depression of the synapses after the LFS. No significant difference, however, was measured between the groups themselves. Inset Averaged (15 sweeps) fEPSPs evoked in slices from St-Im (no significant depression), and St-AE (significant depression of the synapses) groups of rats. Interrupted line represents the baseline response, and the continuous line is the trace of the responses $60 \mathrm{~min}$ after the LFS train

\section{Discussion}

Our results show that a behavioral treatment of short-term environmental enrichment (with or without announcement) improves the long-term effects of chronic social stress in rats on the impairment of reward-related behavior and reduction of hippocampal synaptic plasticity induced by social defeat followed by individual housing. Interestingly, these effects seem to be long lasting since they were present more than 100 days, after termination of the behavioral treatment. More importantly, inclusion of an announcement did have an additional effect on the enrichment-induced restoration of the synaptic plasticity of the hippocampus.

Environmental enrichment with announcement (St-AE) reversed the deteriorating effect of social stress on hippocampal synaptic plasticity. This effect was significantly larger than environmental enrichment alone (St-E group). Although there was no significant difference in LTD expression between the two groups, the expression of LTP 


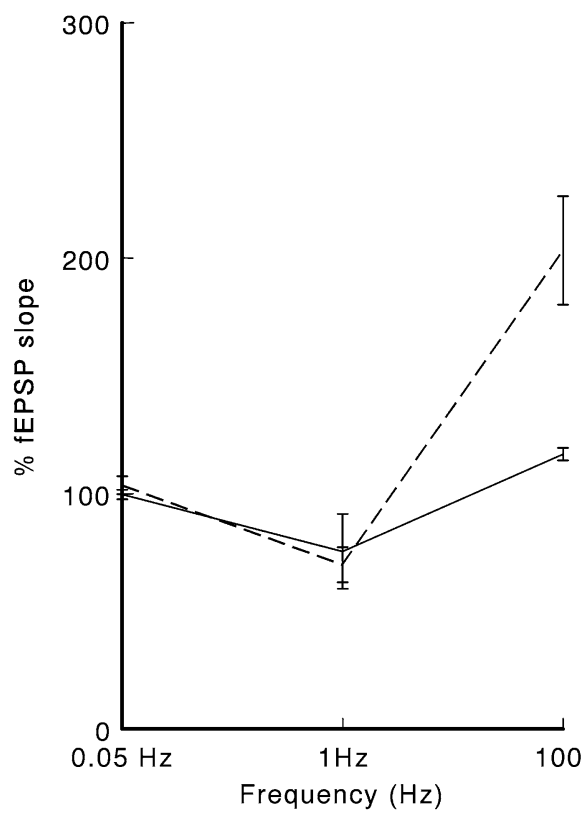

Fig. 5 The frequency response relation in St-E (continuous line) and St-AE (interrupted line) groups of rats. The averaged values of the fEPSP slope recorded $60 \mathrm{~min}$ after LFS $(1 \mathrm{~Hz})$ and HFS $(100 \mathrm{~Hz})$ in both groups are plotted. The baseline responses evoked by the testing stimuli (stimulation frequency of $0.05 \mathrm{~Hz}$ ) were set to $100 \%$. LFS induced depression, and HFS induced potentiation of the synapses in both groups. The plasticity of the synapses (the range of synaptic activity between the levels of depression to the level of potentiation) was much bigger in the St-AE group. Data are presented as mean \pm SEM

was clearly different. The induction mechanisms of LTP and LTD are different. Some factors may affect the induction of LTP, while other factors may affect only LTD. In some situations, however (like in diabetes mellitus), both mechanisms are affected leading into a shift in the frequency-response curve of the synapses (Kamal et al. 2000). Our results showed that only LTP was deteriorated in the stressed, and then restored in the environmentally enriched rats (Fig. 5). This may suggest that LTD induction mechanism was not affected by such behavioral stressful situations. Further research, however, is needed to investigate in this direction. The synaptic plasticity range was significantly wider in the St-AE group compared to St-E group. This difference in the plasticity range was mostly due to enhanced LTP induction in the St-AE group (Fig. 5). The plasticity range was shown to be not significantly different between the Co-AE and St-AE groups. Although the behavioral significance of this finding cannot be determined from these experiments, it is possible that the decrease in the range of transmission plasticity in the hippocampus is related to an impairment performance in spatial learning tasks (Kamal et al. 1998).

It has been argued previously (Van der Harst et al. 2005) that the therapeutic effect of environmental enrichment on chronic stress symptoms might be caused by the effects of physical activity. This seems plausible since it is known that physical activity in previously stressed rats restores hippocampal brain-derived neurotropic factor (BDNF) mRNA levels to baseline (Russo-Neustadt et al. 2001). BDNF is implicated in activity-dependent synaptic plasticity in the hippocampus in several ways: BDNF induces a long-lasting enhancement of synaptic transmission in the hippocampus (Kang and Schuman 1995; Kovalchuk et al. 2002), LTP is impaired in mice lacking BDNF (Korte et al. 1995), and the mRNA level and release of BDNF is increased by LTP inducing stimuli (Patterson et al. 1992; Balkowiec and Katz 2002). These results are related to the evidence that has been gathered in recent years that BDNF expression could be an important agent for therapeutic recovery from depression (Nibuya et al. 1995; Siuciak et al. 1997). The beneficial effects of physical activity for depressive disorders are extensively investigated in clinical studies (Fox 1999; Martinsen 1994; Weyerer and Kupfer 1994), and it is suggested that long-term physical exercise may protect the hippocampus from stress-induced damages (Russo-Neustadt et al. 2000; Ma et al. 2002). The therapeutic efficacy of environmental enrichment can also be explained in terms of opioid-activity: It is known that levels of endogenous opioids (endorphins) increase in response to physical activity (Browne and Segal 1980; Lett et al. 2001; Vaccarino and kastin 2000). Furthermore, the display of a more extensive repertoire of species-specific behavior is argued to be rewarding in itself (Van der Harst et al. 2003b), also resulting in activation of the endorphinergic system. In line with the fact that endorphins are candidates for antidepressant treatment (Broom et al. 2002; Daniel et al. 1992; Emrich et al. 1983), it is possible that enrichedenvironment-induced opioid activity counteracts the effects of chronic stress on reward-sensitivity via activation of the endorphinergic system (Spruijt et al. 2001). The efficacy of the announcement is likely to be mediated by activating dopaminergic systems. Since both treatments (E- and AE-) caused a restoration of the display of anticipatory behavior, the behavioral data alone did not decisively indicate whether announcement has an additional effect on top of the effect of the physical activity on the consequences of chronic stress. The results of the electrophysiological measurements, however, indicate that the inclusion of an announcement did have an additional effect on the enrichment-induced restoration of the synaptic plasticity of the hippocampus. Although both behavioral treatments could restore the LTP-deficit in the hippocampus of socially stressed rats, the degree of potentiation was significantly higher in St-AE as compared to St-E. The effects of both therapies are long-lasting since the electrophysiological measurements were conducted more than 100 days after termination of the behavioral treatments. Furthermore, when the amount of LTP in the socially stressed rats that 
were subjected to the different treatments is compared to non-defeated socially housed control rats, it appears that the potentiation of the hippocampal synapses of St-E is not completely restored to a 'normal' level (approximately $200 \%$, see Table 3). This is, as reported before (Von Frijtag et al. 2001; Artola et al. 2006), also the case for imipramine-treated rats. St-AE, on the other hand, did reverse the chronic-stress induced long-term changes of hippocampal synaptic plasticity completely. The additional effect of the anticipatory phase before the actual transfer to the enriched cage might be explained by the fact that 'expectation' of a reward triggers dopamine release (Schultz 1998; O'Doherty et al. 2002). Since dopaminergic activity (among other things) is altered in depressive disorders, it is likely that the therapeutic efficacy of anticipation counteracts the effects of chronic stress via activation of dopaminergic systems. This is in line with the knowledge that dopamine appears to be involved in the modulation of hippocampal synaptic plasticity (Kang et al. 2000; Lezcano and Bergson 2002; Otmakhova and Lisman 1996; Schmelzeis and Mittleman 1996). It must be noted, however, that anticipation in combination with a sucrose reward has not been successful in reversing the chronic stress-induced impairment. Namely, the control group (St-W) was subjected to an anticipation-on-sucrose test, but the impaired hippocampal plasticity of St-W was not restored after exposure to this anticipation-on-sucrose test. This is in line with the results of a previous study (Von Frijtag et al. 2002) in which a previous anticipation-of-sucrose test did not affect the impairment of reward-related behavior in a second test. Thus, it is likely that the therapeutic efficacy of anticipation on environmental enrichment is caused via dopaminergic activity. This is in line with the fact that environmental enrichment alone did not cause a complete restoration of LTP to a 'normal' level (i.e. a 100\% increase). That the harmful effects of chronic stress can be compensated by reward-related activities has been suggested before (Weyerer and Kupfer 1994). The hippocampus seems a useful area of interest because, besides its sensitivity to stress, it is also involved in the modulation of reward and incentive motivation (Wise 1989; Schmelzeis and Mittleman 1996; Bardo 1998; Rao et al. 1999).

In conclusion, we show here that announced short-term environmental enrichment has a therapeutic efficacy on stress-induced alterations of both reward-sensitivity and hippocampal synaptic plasticity. Importantly, these are long-lasting effects that remain present after termination of the treatment. Since this behavioral treatment, based on rewarding activities, has such strong therapeutic characteristics that it can reverse chronic stress-induced depressivelike symptoms in rats, it is obvious that it should also be applicable to counteract the effects of other (less severe) forms of stress. Therefore, our findings may have therapeutic relevance in the case of welfare problems in both man and captive animals.

Open Access This article is distributed under the terms of the Creative Commons Attribution Noncommercial License which permits any noncommercial use, distribution, and reproduction in any medium, provided the original author(s) and source are credited.

\section{References}

American Psychiatric Association (1994) Diagnostic and statistical manual of mental disorders (DSM-IV), 4th edn. APA, Washington $\mathrm{DC}$

Artola A, Von Frijtag JC, Fermont PCJ, Gispen W-H, Schrama LH, Kamal A, Spruijt BM (2006) Long-lasting modulation of the induction of LTD and LTP in rat hippocampal CA1 by behavioral stress and environmental enrichment. Eur J Neurosci 23:261-272

Balkowiec A, Katz DM (2002) Cellular mechanisms regulating activity- dependent release of native brain-derived neurotrophic factor from hippocampal neurons. J Neurosci 22:10399-10407

Bardo MT (1998) Neuropharmacological mechanisms of drug reward: beyond dopamine in the nucleus accumbens. Crit Rev Neurobiol 12:37-67

Broom DC, Jutkiewicz EM, Rice KC, Traynor JR, Woods JH (2002) Behavioral effects of delta-opioid receptor agonists: potential antidepressants? Jpn J Pharmacol 90:1-6

Browne RG, Segal DS (1980) Behavioral activating effects of opiates and opioid peptides. Biol Psychiatry 15(1):77-85

Buwalda B, Kole MHP, Veenema AH, Huininga M, de Boer SF, Korte SM, Koolhaas JM (2005) Long-term effects of social stress on brain and behavior: a focus on hippocampal functioning. Neurosci Biobehav Rev 29:83-97

Carboni L, Piubelli C, Pozzato C, Astner H, Arban R, Righetti PG, Hamdan M, Domenici E (2006) Proteomic analysis of rat hippocampus after repeated psychosocial stress. Neuroscience 137(4):1237-1246

Daniel M, Martin AD, Carter J (1992) Opiate receptor blockade by naltrexone and mood state after acute physical activity. Br J Sports Med 26:111-115

De Kloet RE, Oitzl MS, Joëls M (1999) Stress and cognition: are corticosteroids good or bad guys? Trends Neurosci 22(10):422-426

Diamond DM, Rose GM (1994) Stress impairs LTP and hippocampal dependent memory. Ann N Y Acad Sci 746:411-414

Emrich HM, Gunther R, Dose M (1983) Current perspectives in the pharmacopsychiatry of depression and mania. Neuropharmacology 22:385-388

Foster TC, Gagne J, Massicotte G (1996) Mechanism of altered synaptic strength due to experience: relation to long-term potentiation. Brain Res 736:243-250

Fox KR (1999) The influence of physical activity on mental wellbeing. Public Health Nutr 2:411-418

Foy MR, Stanton ME, Levine S, Thompson RF (1987) Behavioural stress impairs long-term potentiation in rodent hippocampus. Behav Neural Biol 48(1):138-149

Kamal A, Biessels GJ, Gispen WH, Urban IJA (1998) Increasing age reduces expression of long-term depression and dynamic range of transmission plasticity in CA1 field of the rat hippocampus. Neuroscience 83(3):707-715

Kamal A, Biessels GJ, Duis SEJ, Gispen WH (2000) Learning and hippocampal synaptic plasticity in streptozotocin-diabetic rats: interaction of diabetes and ageing. Diabetologia 43:500-506

Kang H, Schuman EM (1995) Long-lasting neurotrophin-induced enhancement of synaptic transmission in the adult hippocampus. Science 267:1658-1662 
Kang DK, Kim KO, Lee SH, Lee YS, Son H (2000) c-Fos expression by dopaminergic receptor activation in rat hippocampal neurons. Mol Cells 10:546-551

Kim JJ, Yoon K (1998) Stress: metaplastic effects in the hippocampus. Trends Neurosci 21(12):505-509

Kim JJ, Foy MR, Thompson RF (1996) Behavioral stress modifies hippocampal plasticity through $N$-methyl-D-Aspartate receptor activation. Proc Natl Acad Sci USA 93:4750-4753

Korte M, Carroll P, Wolf E, Brem G, Thoenen H, Bonhoeffer T (1995) Hippocampal long-term potentiation is impaired in mice lacking brain-derived neurotrophic factor. Proc Natl Acad Sci USA 92:8856-8860

Kovalchuk Y, Hanse E, Kafitz KW, Konnerth A (2002) Postsynaptic induction of BDNF- mediated long-term potentiation. Science 295:1729-1734

Lett BT, Grant VL, Koh MT (2001) Naloxone attenuates the conditioned place preference induced by wheel running in rats. Physiol Behav 72:355-358

Lezcano N, Bergson C (2002) D1/D5 dopamine receptors stimulate intracellular calcium release in primary cultures of neocortical and hippocampal neurons. J Neurophysiol 87:2167-2175

Ma Q, Wang J, Liu HT, Chao FH (2002) Attenuation of chronic stressinduced hippocampal damages following physical exercise. Sheng Li Xue Bao 54:427-430

Martinsen EW (1994) Physical activity and depression: clinical experience. Acta Psychiatr Scand Suppl 377:23-27

McEwen BS (1999) Stress and hippocampal plasticity. Annu Rev Neurosci 22:105-122

Nibuya M, Morinobu S, Duman RS (1995) Regulation of BDNF and trkB mRNA in the rat brain by chronic electroconvulsive seizure and antidepressant drug treatments. J Neurosci 5(11):7539-7547

O’Doherty JP, Deichmann R, Critchley HD, Dolan RJ (2002) Neural responses during anticipation of a primary taste reward. Neuron 33(5):815-826

Otmakhova NA, Lisman JE (1996) D1/D5 dopamine receptor activation increases the magnitude of early long-term potentiation at CA1 hippocampal synapses. J Neurosci 16:7478-7486

Patterson SL, Grover LM, Schwartzkroin PA, Bothwell M (1992) Neurotrophin expression in rat hippocampal slices: a stimulus paradigm inducing LTP in CA1 evokes increases in BDNF and NT-3 mRNAs. Neuron 9:1081-1088

Pavlides C, Nivon LG, McEwen BS (2002) Effects of chronic stress on hippocampal long- term potentiation. Hippocampus 12:245257

Rao BS, Raju TR, Meti BL (1999) Increased numerical density of synapses in CA3 region of hippocampus and molecular layer of motor cortex after self-stimulation rewarding experience. Neuroscience 91:799-803

Russo-Neustadt AA, Beard RC, Huang YM, Cotman CW (2000) Physical activity and antidepressant treatment potentiate the expression of specific brain-derived neurotrophic factor transcripts in the rat hippocampus. Neuroscience 101:305-312
Russo-Neustadt A, Ha T, Ramirez R, Kesslak JP (2001) Physical activity-antidepressant treatment combination: impact on brain-derived neurotrophic factor and behavior in an animal model. Behav Brain Res 120:87-95

Schmelzeis MC, Mittleman G (1996) The hippocampus and reward: effects of hippocampal lesions on progressive-ratio responding. Behav Neurosci 110(5):1049-1066

Schultz W (1998) Predictive reward signal of dopamine neurons. J Neurophysiol 80(1):1-27

Shakesby AC, Anwyl R, Rowan MJ (2002) Overcoming the effects of stress on synaptic plasticity in the intact hippocampus: rapid actions of serotonergic and antidepressant agents. J Neurosci 22(9):3638-3644

Siuciak JA, Lewis DR, Wiegand SJ, Lindsay RM (1997) Antidepressant-like effect of brain- derived neurotrophic factor BDNF. Pharmcol Biochem Behav 56(1):131-137

Spruijt BM, Van den Bos R, Pijlman FTA (2001) A concept of welfare based on reward evaluating mechanisms in the brain: anticipatory behaviour as an indicator for the state of reward systems. Appl Anim Behav Sci 72:145-171

Vaccarino AL, Kastin AJ (2000) Endogenous opiates: 1999. Peptides 21:1975-2034

Van Dam EJM, Kamal A, Artola A, de Graan PNE, Gispen WH, Ramakers GMJ (2004) Group I metabotropic glutamate receptors regulate the frequency-response function of hippocampal CA1 synapses for the induction of LTP and LTD. Eur J Neurosci 19:112-118

Van der Harst JE, Fermont PCJ, Bilstra AE, Spruijt BM (2003a) Access to enriched housing is rewarding to rats as reflected by their anticipatory behaviour. Anim Behav 66:493-504

Van der Harst JE, Baars JM, Spruijt BM (2003b) Standard housed rats are more sensitive to rewards than enriched housed rats as reflected by their anticipatory behaviour. Behav Brain Res 142:151-156

Van der Harst JE, Baars JM, Spruijt BM (2005) Announced rewards counteract the impairment of anticipatory behaviour in socially stressed rats. Behav Brain Res 161:183-189

Von Frijtag JC, Reijmers LG, Van der Harst JE, Leus IE, Van den Bos R, Spruijt BM (2000) Defeat followed by individual housing results in long-term impaired reward- and cognition related behaviours in rats. Behav Brain Res 117:137-146

Von Frijtag JC, Kamal A, Reijmers LG, Schrama LH, van den Bos R, Spruijt BM (2001) Chronic imipramine treatment partially reverses the long-term changes of hippocampal synaptic plasticity in socially stressed rats. Neurosci Lett 309:153-156

Von Frijtag JC, van den Bos R, Spruijt BM (2002) Imipramine restores the long-term impairment of appetitive behavior in socially stressed rats. Psychopharmacology 162:232-238

Weyerer S, Kupfer B (1994) Physical exercise and psychological health. Sports Med 17:108-116

Wise RA (1989) The brain and reward. In: Liebman J, Cooper J (eds) The neuropharmacological basis of reward. Oxford University Press, Oxford, pp 55-78 